\title{
Combination of Biorthogonal Wavelet Hybrid Kernel OCSVM with Feature Weighted Approach Based on EVA and GRA in Financial Distress Prediction
}

\author{
Chao Huang, Fei Gao, and Hongyan Jiang \\ Department of Management Science and Engineering, School of Economics and Management, Southeast University, Jiangsu, \\ Nanjing 210096, China \\ Correspondence should be addressed to Chao Huang; huangchao@seu.edu.cn
}

Received 16 June 2014; Accepted 15 September 2014; Published 29 September 2014

Academic Editor: Wei-Chiang Hong

Copyright (C) 2014 Chao Huang et al. This is an open access article distributed under the Creative Commons Attribution License, which permits unrestricted use, distribution, and reproduction in any medium, provided the original work is properly cited.

\begin{abstract}
Financial distress prediction plays an important role in the survival of companies. In this paper, a novel biorthogonal wavelet hybrid kernel function is constructed by combining linear kernel function with biorthogonal wavelet kernel function. Besides, a new feature weighted approach is presented based on economic value added (EVA) and grey relational analysis (GRA). Considering the imbalance between financially distressed companies and normal ones, the feature weighted one-class support vector machine based on biorthogonal wavelet hybrid kernel (BWH-FWOCSVM) is further put forward for financial distress prediction. The empirical study with real data from the listed companies on Growth Enterprise Market (GEM) in China shows that the proposed approach has good performance.
\end{abstract}

\section{Introduction}

Financial distress is a term in corporate finance used to indicate a condition when a company has serious losses and becomes insolvent with liabilities. Sometimes financial distress can lead to bankruptcy [1]. Financial distress prediction has been a good practical tool for distinguishing companies in distress from those healthy, and it also guarantees the survival of companies [2, 3].

Since the 1960s, enormous efforts have been made to construct efficient financial distress prediction models, but improving the models' accuracy is still a challenging task. Many statistical methods such as discriminant analysis (DA) [4], logistic regression [5], and profit regression [6] have been applied to financial distress prediction in early studies [7]. After that, artificial intelligence methods such as genetic algorithm [8], rough sets [9], case-based reasoning [10], and artificial neural networks (ANNs) [11] have been proposed. In recent years, a number of studies about financial distress prediction have been announced concerning support vector machine (SVM), since the SVM has better performance in nonlinear approximation and local optimal solutions.
SVM is a class of typical machine learning algorithms and its main idea is to minimize the upper bound of the generalization error. Usually it maps the input vectors into a high-dimensional feature space through some nonlinear mapping. The SVM is a powerful method for classification and has shown promising performance in financial distress prediction. Huang et al. evaluate the performance of the SVM in credit rating prediction and prove that the model based on the SVM has a better explanatory power than the model based on back propagation neural networks (BPNN) [12]. Shin et al. investigate the efficacy of applying the SVM to bankruptcy prediction and the results demonstrate that the SVM approach also outperforms the BPNN in prediction [13]. Härdle et al. propose an application of visualization techniques at different stages of corporate default analysis based on the SVM and also conclude that the SVM model is always dominating the DA and logistic regression with regard to accuracy ratio [14].

The SVM is a very specific type of learning algorithms characterized by the use of kernel functions, which realizes the nonlinear mapping from the original space to a highdimensional feature space. Kernel function has received 
tremendous attention as it has a significant impact on the performance and prediction accuracy of the SVM. Kernels commonly used in the SVM include Gaussian kernel, polynomial kernel, and spline kernel. Wavelet has been widely used in constructing kernel functions recently because of its excellent performance in nonlinear data processing. Zhang et al. propose a SVM based on a Morlet wavelet kernel and the experiments show its feasibility and validity in approximation and classification [15]. Wei presents the SVM based on Morlet wavelet kernel, which yields more accurate prediction than the SVM based on Gaussian kernel [16]. Yang and Wang apply the SVM based on the Morlet and Mexico hat wavelet kernels to improve the detection accuracy and deduce false positive rate of distributed denial of service attack detection [17]. Among the wavelets, biorthogonal wavelet excels in nonlinear signal approximation with high smoothness, compact support, and high vanishing moment. Biorthogonal wavelet is derived from a multiresolution analysis generated by a pair of dual scaling functions and has been found very useful in applications such as signal processing and image compression [18]. To the best of our knowledge, few researches work on constructing biorthogonal wavelet kernel function.

In order to take full advantage of different kernel functions' mapping abilities, hybrid kernel function combined with multiple kernel functions is emphasized. Linear and nonlinear combinations are the main methods to construct hybrid kernel function. Linear combinations of polynomials and Gaussian kernel [19] and wavelet and RBF kernel are employed [20] while the results demonstrate that SVMs with hybrid kernels beat all single-kernel models in learning performance and prediction accuracy. Some researchers concentrate on the nonlinear combination of multiple kernels for SVMs so that useful information generated from the nonlinear interaction of different kernels will not be neglected. $\mathrm{Li}$ and Sun propose SVMs based on the nonlinear combination of multiple kernels and its effectiveness is testified by empirical studies [21]. Cortes et al. observe a considerable performance improvement in nonlinear combinations of kernels [22]. However, hybrid kernel SVM is rarely applied to financial distress prediction.

Feature weighting, which assigns different coefficients to different features with each coefficient indicating the relative importance of the corresponding feature to the given learning task (e.g., classifications), has been studied by machine learning researchers and some kind of performance improvements may be obtained [23]. Grey relational analysis (GRA) proposed by Deng aims for dealing with poor, incomplete, and uncertain systems. GRA model is used to analyze various factors' dynamic relations and the changes with time in order to find the key factors in prediction and decision-making. According to Song et al. [24], the change trends of the two factors are basically the same, indicating that the two factors are closely related and the grey relational degree (GRD) between them is higher. Apparently, the GRDs between the financial situation and financial indicators of companies can reflect the correlations between them. The higher the GRD is, the greater the relevance is and the more important the financial indicator should be while evaluating the financial situation.
The GRA models provide appropriate tools for examining a rank of order of multiple objects with semblance from an objective. Owing to the usefulness and advantages of the GRA, the GRA was applied to financial distress prediction recently. Kung and Wen use six financial indicators to classify twenty items of financial ratios as research variables and apply the GRA to find the significant financial ratio variables affecting the financial situation of venture capital enterprises in Taiwan [25]. Lin and Wu propose a new approach of the GRA to construct a financial crisis warning system for banking industry and the empirical results illustrate that in the prediction of financial crisis as well as financially sound banks, the proposed GRA model demonstrates better prediction accuracy [26]. Lin et al. investigate the efficacy of applying the hybrid distress prediction model based on the GRA and rough set to financial distress prediction and the results demonstrate that the hybrid approach can significantly improve the prediction accuracy [27]. Chuang uses the GRA to evaluate the importance of the features to provide a ranking of the features, and it makes a better predictive performance to enhance the accuracy of distress prediction [28].

Economic value added (EVA) is a financial performance measure capable of presenting the financial situation of a company. Unlike credit rating used in many countries [29, 30] or special treatment (ST) used in the securities market of China [31], The EVA is a quantitative description of the financial situation. The larger the value of the EVA is, the better the financial situation. However, few researches combine the GRA and the EVA for weighting financial indicators and predicting financial distress.

The purpose of this paper is to propose a new approach combining biorthogonal wavelet hybrid kernel one-class SVM with feature weighted approach based on the EVA and the GRA for financial distress prediction. This paper is organized as follows. The next section focuses on the construction of hybrid kernel function based on biorthogonal wavelet kernel and linear kernel. Section 3 discusses the feature weighted approach based on the GRA and the EVA. In Section 4, we propose the feature weighted one-class SVM based on biorthogonal wavelet hybrid kernel (BWH-FWOCSVM) for financial distress prediction. Section 5 presents the experimental results of the proposed method. The concluding remarks are given in Section 6.

\section{Construction of Biorthogonal Wavelet Hybrid Kernels Function}

Assuming $\mathscr{X}$ is a subset of $n$-dimensional real space $R^{n}$, there is a mapping $\Phi: x \mapsto \Phi(x), x \in \mathscr{X}, \Phi(x) \in \mathscr{H}$ satisfying $K\left(x, x^{\prime}\right)=\left\langle\Phi(x), \Phi\left(x^{\prime}\right)\right\rangle$, where $\mathscr{H}$ is the Hilbert space and $\langle\cdot, \cdot\rangle$ denotes the inner product, and then the function $K\left(x, x^{\prime}\right)$ defined on $\mathscr{X} \times \mathscr{X}$ is called the kernel function. Kernel function transforms nonlinear problems in the input space into linear problems in the feature space. Consequently, sample point $\mathscr{X}$ in the input space can be mapped to a high dimensional feature space $\mathscr{H}$ by an appropriate mapping $\Phi$ : $x \mapsto \Phi(x)$. 
It is well known that high smoothness, compact support, and high vanishing moment are the three most important properties of a biorthogonal wavelet, which has been found very useful in various applications such as signal processing and image compression.

Supposing $\psi(t)$ is a biorthogonal wavelet function and $\psi^{d}(t)$ is the dual biorthogonal wavelet function with scaling functions $\phi$ and $\phi^{d}$, respectively, the corresponding scale coefficients of $\phi$ and $\phi^{d}$ are $a(n)$ and $a^{d}(n)$ satisfy

$$
\begin{aligned}
\sum_{n \in Z} a(n) a^{d}(n+2 \beta) & =\delta(\beta) \\
& = \begin{cases}0, & \beta \in Z, \beta \neq 0, \\
1, & \beta=0 .\end{cases}
\end{aligned}
$$

Assuming $\widehat{\phi}(\omega)$ and $\widehat{\phi^{d}}(\omega)$ are the Fourier transformations of $\phi$ and $\phi^{d}$, respectively, then $\widehat{\phi}(\omega)=\int_{-\infty}^{\infty} \phi(t) e^{-i \omega t} d t$ and $\widehat{\phi^{d}}(\omega)=\int_{-\infty}^{\infty} \phi^{d}(t) e^{-i \omega t} d t$. Biorthogonal Riesz basis in $L^{2}(R)$ is obtained by translating and scaling $\psi(t)$ and $\psi^{d}(t)$ if for any $\varepsilon>0$, there exists $C>0$ satisfying $\hat{\phi}(\omega) \leq$ $C(1+\omega)^{-1 / 2-\varepsilon}$ and $\widehat{\phi^{d}}(\omega) \leq C(1+\omega)^{-1 / 2-\varepsilon}$, and $\phi$ and $\phi^{d}$ have sufficient attenuation in the frequency domain while they are also meeting $\int_{R} \phi(x) \phi^{d}(x-\beta) d x=\delta(\beta)$.

Therefore, any functions in $L^{2}(R)$ can be expanded by biorthogonal wavelet function, meaning for every $f(t) \in L_{2}(R), f(t)=\sum_{j \in Z} \sum_{n \in Z}\left\langle f, \psi_{j, n}^{d}\right\rangle \psi_{j, n}(t)=$ $\sum_{j \in Z} \sum_{n \in Z}\left\langle f, \psi_{j, n}\right\rangle \psi_{j, n}^{d}(t)$, where $\psi_{j, n}(t)=2^{j / 2} \psi\left(2^{j} t-n\right)$ and $\psi_{j, n}^{d}(t)=2^{j / 2} \psi^{d}\left(2^{j} t-n\right)$.

Meanwhile, a multiresolution analysis $\left\{V_{j}, V_{j}^{d}\right\}_{j \in Z}$ in $L_{2}(R)$ can be obtained, where space $V_{j}$ is generated from $\left\{\phi_{j, n}\right\}_{n \in Z}$ and space $V_{j}^{d}$ is generated from $\left\{\phi_{j, n}^{d}\right\}_{n \in Z}$. Accordingly, for any $f(t) \in V_{j}$, its expansion is $f(t)=$ $\sum_{n \in Z}\left\langle f, \phi_{j, n}^{d}\right\rangle \phi_{j, n}(t)$, where $\phi_{j, n}(t)=2^{j / 2} \phi\left(2^{j} t-n\right)$ and $\phi_{j, n}^{d}(t)=2^{j / 2} \phi^{d}\left(2^{j} t-n\right)$.

Based on the analysis above, we can construct a biorthogonal wavelet kernel function as shown in (2), where $x, x^{\prime} \in$ $\mathscr{X} \subseteq R^{n}$

$$
K\left(x, x^{\prime}\right)=\sum_{n \in Z} \phi_{j, n}(x) \phi_{j, n}^{d}\left(x^{\prime}\right) .
$$

Limited to the admissibility of positive definite kernel, an effective kernel function $K\left(x, x^{\prime}\right)$ should be symmetric and positive definite. We will prove that the biorthogonal wavelet kernel function constructed by (2) satisfies the conditions.

As mentioned above, $\phi(t)$ and $\phi^{d}(t)$ are a pair of biorthogonal dual scaling functions so that for any $f(t) \in V_{j} \cap V_{j}^{d}$, the following equations can be obtained:

$$
\begin{aligned}
f(x) & =\sum_{n \in Z}\left\langle f, \phi_{j, n}^{d}\right\rangle \phi_{j, n}(x) \\
& =\left\langle f(\cdot), \sum_{n \in Z} \phi_{j, n}^{d}(\cdot) \phi_{j, n}(x)\right\rangle,
\end{aligned}
$$

$$
\begin{aligned}
f(x) & =\sum_{n \in Z}\left\langle f, \phi_{j, n}\right\rangle \phi_{j, n}^{d}(x) \\
& =\left\langle f(\cdot), \sum_{n \in Z} \phi_{j, n}(\cdot) \phi_{j, n}^{d}(x)\right\rangle .
\end{aligned}
$$

From (3), $\sum_{n \in Z} \phi_{j, n}(x) \phi_{j, n}^{d}(\cdot)-\sum_{n \in Z} \phi_{j, n}(\cdot) \phi_{j, n}^{d}(x)=0$. And then we will have

$$
\begin{aligned}
K\left(x, x^{\prime}\right) & =\sum_{n \in Z} \phi_{j, n}(x) \phi_{j, n}^{d}\left(x^{\prime}\right) \\
& =\sum_{n \in Z} \phi_{j, n}\left(x^{\prime}\right) \phi_{j, n}^{d}(x)=K\left(x^{\prime}, x\right) .
\end{aligned}
$$

Obviously, the kernel function $K\left(x, x^{\prime}\right)$ in (2) is symmetric.

Proving the positive definiteness of $K\left(x, x^{\prime}\right)$ equals to prove that for any $\forall x_{1}, x_{2}, \ldots, x_{l} \in R$, the Gram matrix of $K\left(x, x^{\prime}\right)$ is positive semidefinite. For any $a_{i}, a_{k} \in R$, we can obtain

$$
\begin{aligned}
& \sum_{i, k=1}^{l} a_{i} a_{k} K\left(x_{i}, x_{k}\right) \\
& \quad=\sum_{i, k=1}^{l} \sum_{n \in Z} \sum_{m \in Z} a_{i} a_{k}\left\langle\phi_{j, n}^{d}, \phi_{j, m}^{d}\right\rangle \phi_{j, n}\left(x_{i}\right) \phi_{j, m}\left(x_{k}\right) \\
& =\left\langle\sum_{i=1}^{l} \sum_{n \in Z} a_{i} \phi_{j, n}\left(x_{i}\right) \phi_{j, n}^{d}(\cdot), \sum_{k=1}^{l} \sum_{m \in Z} a_{k} \phi_{j, m}\left(x_{j}\right) \phi_{j, m}^{d}(\cdot)\right\rangle \\
& =\left\|\sum_{i=1}^{l} \sum_{n \in Z} a_{i} \phi_{j, n}\left(x_{i}\right) \phi_{j, n}^{d}(\cdot)\right\|^{2} \geq 0 .
\end{aligned}
$$

Apparently $K\left(x, x^{\prime}\right)$ is also a positive definite function. As a consequence, the biorthogonal wavelet kernel function $K\left(x, x^{\prime}\right)$ in $(2)$ is effective.

Local kernel and global kernel are two basic types of kernels. A kernel possessing translation invariance is a local kernel, which satisfies $K\left(x, x^{\prime}\right)=K\left(x-x^{\prime}\right)$. While a kernel having rotational invariance is a global kernel, which means for every $\varepsilon \geq 0$, there must be $K(\varepsilon) \geq 0, K^{\prime}(\varepsilon) \geq 0$, $K^{\prime}(\varepsilon)+\varepsilon K^{\prime}(\varepsilon) \geq 0$, and $K\left(x, x^{\prime}\right)=f\left(\left\langle x \cdot x^{\prime}\right\rangle\right)$.

The biorthogonal wavelet kernel function is definitely a local kernel because it is symmetric, satisfying $K\left(x-x^{\prime}\right)=$ $K\left(x^{\prime}, x\right)=K\left(x, x^{\prime}\right)$. Obviously, the linear kernel $K\left(x, x^{\prime}\right)=$ $x \cdot x^{\prime}$ is a typical global kernel. According to [32], hybrid kernel function has a superior performance compared with the single kernel function since the mixtures of kernels have advantages of generation ability of the global kernel and learning capacity of the local kernel. Thus, by combining linear kernel function and biorthogonal wavelet kernel function, we construct the biorthogonal wavelet hybrid kernel function $K_{M}\left(x, x^{\prime}\right)$ :

$$
K_{M}\left(x, x^{\prime}\right)=\rho K_{1}\left(x, x^{\prime}\right)+(1-\rho) K_{2}\left(x, x^{\prime}\right),
$$


where $K_{1}\left(x, x^{\prime}\right)$ is the biorthogonal wavelet kernel function, $K_{2}\left(x, x^{\prime}\right)$ is the linear kernel function, $\rho$ represents the weighting coefficient and $\rho \in[0,1]$. In this paper, because of its good performance in signal processing, Cdf9/7 biorthogonal wavelet is selected to construct $K_{1}\left(x, x^{\prime}\right)$ and the details of $\mathrm{Cdf9} / 7$ biorthogonal wavelet refers to [33]. Then, biorthogonal wavelet hybrid kernel function $K_{M}\left(x, x^{\prime}\right)$ can be expanded to the form

$$
\begin{aligned}
K_{M}\left(x, x^{\prime}\right)= & \rho \sum_{k \in Z} 2^{j}(2 \pi)^{-2} \int_{-\pi}^{\pi} \phi(\omega) e^{i \omega\left(2^{j} x-k\right)} d \omega \\
& \times \int_{-\pi}^{\pi} \widehat{\phi}\left(\omega^{\prime}\right) e^{i \omega^{\prime}\left(2^{j} x^{\prime}-k\right)} d \omega^{\prime} \\
& +(1-\rho) x \cdot x^{\prime} .
\end{aligned}
$$

\section{Financial Indicator Weighting Based on EVA and GRA}

The EVA is a quantitative description of the financial situation. The larger the value of EVA is, the better the financial situation. The EVA focuses on shareholder value and the role of capital cost including costs of both debt and equity. A positive EVA signifies that value has been created for shareholders. In other words, this enterprise has high profitability and good financial situation, while a negative EVA indicates value destruction with financial distress which needs to make an early warning [34]. The EVA can be defined as the firm operating profit after taxes subtracting the cost of capital, which can be calculated as follows:

$$
\mathrm{EVA}=\operatorname{NOPAT}-(D+E) * \mathrm{WACC},
$$

where NOPAT is the net operating profit after taxes, $D$ is the debt book value, $E$ is the equity book value, and WACC is the weighted average cost of capital. The information needed to compute the EVA mainly comes from accounting data, which needs to go through some adjustments in order to correct the distortions in accounting information [35]. The most important adjustments include the adjustments of NOPAT, $D, E$, and WACC [36-38]. Consider

$$
\mathrm{NOPAT}=\mathrm{NP}+\mathrm{LIC}+\mathrm{OAIC}+\mathrm{NNOI} \times(1-T)+\mathrm{DTI},
$$

where NP is the net profit, LIC is the loan impairment number changes of this year, OAIC is the other assets impairment number changes of this year, NNOI is the net nonoperating income, $T$ is the tax rate, and DTI is the deferred tax increases.

Consider

$$
D=S_{\mathrm{TL}}+\mathrm{LO}+L_{\mathrm{TL}}+\mathrm{BP},
$$

where $S_{\mathrm{TL}}$ is the short-term loan, LO is the long-term loan in one year, $L_{\mathrm{TL}}$ is the long-term loan, and $\mathrm{BP}$ is the bonds payable.

Consider

$$
E=\mathrm{MSI}+\mathrm{SE} \text {, }
$$

where MSI is the minority stockholder's interest and SE is the stockholders' equity.

Consider

$$
\mathrm{WACC}=\frac{E}{D+E} \times K_{E}+\frac{D(1-T)}{D+E} \times K_{D},
$$

where $K_{E}$ is the cost of equity and $K_{D}$ is the cost of debt capital.

GRA is considered to be an analysis of the geometric proximity between different discrete sequences within a system. The proximity is described by the GRD, which is regarded as a measure of the similarities of discrete data that can be arranged in a sequential order [39]. In this paper, the GRA is adopted for the description of the correlation between financial situation (represented by the EVA) and financial indicators.

There are $n$ companies, each with $m$ financial indicators. $e_{0}(k)$ represents the EVA of the $k$ th company and all the EVAs compose the sequence $E_{0}=\left\{e_{0}(1), e_{0}(2), \ldots, e_{0}(n)\right\}$. $x_{i}(k)$ represents the $i$ th financial indicator of the $k$ th company, and the sequence $X_{i}=\left\{x_{i}(1), x_{i}(2), \ldots, x_{i}(n)\right\}(i=$ $1,2, \ldots, m)$ consists of $x_{i}(k)(k=1,2, \ldots, n) . E_{0}$ is defined as the reference sequence, while $X_{i}(i=1,2, \ldots, m)$ is the comparison sequences. To determine the GRD between the reference and comparison sequences, a discrete function of the grey relational coefficient is constructed as follows:

$$
\xi_{0 i}(k)=\frac{\Delta_{\min }+\rho \Delta_{\max }}{\Delta_{0 i}(k)+\rho \Delta_{\max }},
$$

where

$$
\Delta_{0 i}=\left|x_{i}(k)-e_{0}(k)\right|
$$

is the absolute value of the difference between the reference and the $i$ th comparison sequence. $\Delta_{\max }=\max _{i} \max _{k}\left\{\Delta_{0 i}\right\}$ and $\Delta_{\text {min }}=\min _{i} \min _{k}\left\{\Delta_{0 i}\right\}$ are the minimal and maximal proximity, respectively. Meanwhile, $\rho \in(0,1]$ is the coefficient to distinguish and $\rho=0.5$ is generally adopted in most studies. Hence, the GRD between the $i$ th financial indicator and the financial situation of the $k$ th company is

$$
r_{0 i}=r\left(e_{0}, x_{i}\right)=\sum_{k=1}^{n} \omega(k) \cdot \xi_{0 i}(k),
$$

where $\omega(k)$ is the weight of the grey relational coefficient $\xi_{0 i}(k)$ and $\omega(k)=1 / n(k=1,2, \ldots, n)$ are adopted in this study as often used in the literatures. $r_{0 i}$ represents the relevance of the $i$ th financial indicator and the financial situation and is regarded as the weighting of the $i$ th financial indicator.

\section{EVA-FWOCSVM Based on Biorthogonal Wavelet Hybrid Kernel Function}

The feature weighted SVM is a SVM constructed by the feature weighted kernel function $K_{p}$ :

$$
K_{p}\left(x_{i}, x_{j}\right)=K\left(x_{i}^{T} P, x_{j}^{T} P\right)
$$


where $K$ is a kernel function in $X \times X, X \in R^{n}$ and $P=$ $\operatorname{diag}\left(r_{01}, r_{02}, \ldots, r_{0 m}\right)$ is the feature weighting matrix, $r_{0 i}$ is the GRD between the $i$ th financial indicator and financial situation and is calculated by (11). As the weight of the indicator, $r_{0 i}$ is capable of changing the geometry of the feature space by scaling the geometry of the input space. Through the scaling, a more suitable hyperplane is generated in order to improve the classification performance of the SVM.

The feature weighted biorthogonal wavelet hybrid kernel function based on the EVA is shown in (17) by substituting (7) into (16)

$$
\begin{aligned}
K_{\mathrm{MP}}\left(x, x^{\prime}\right)= & \rho \sum_{k \in Z} 2^{j}(2 \pi)^{-2} \\
& \times \int_{-\pi}^{\pi} \phi(\omega) e^{i \omega\left(2^{j} x^{T} P-k\right)} d \omega \\
& \times \int_{-\pi}^{\pi} \widehat{\phi}\left(\omega^{\prime}\right) e^{i \omega^{\prime}\left(2^{j} x^{\prime T} P-k\right)} d \omega^{\prime} \\
& +(1-\rho) x^{T} P P^{T} x^{\prime} .
\end{aligned}
$$

The SVM model is originally designed for binary classification, where it is typically assumed that the numbers of training data for both classes are balanced. However, in real world applications, there is often little or even no data at all available for one of the classes, in other words, one of the classes has a large sample number and the other has a small sample number. For example, in the financial distress prediction, there are only a few companies with financial problems. As a consequence, the accuracy loss of the SVM for binary classification is unavoidable. One-class SVM (OCSVM) model is proposed to improve the classification accuracy by making up for the imbalance of the numbers of both classes [40].

Suppose the training sample is $D=\left\{x_{i}, y_{i}\right\}_{i=1}^{l}$, where $x_{i} \in R^{m}$ is the input vector and $y_{i} \in\{-1,+1\}$ is the class label. In this paper, the class label is decided by the value of the EVA; that is, a positive EVA means good financial situation of the company and the corresponding class label is +1 , while a negative EVA shows the company is trapped in financial crisis and its class label is -1 .

According to [40], the construction of the feature weighted one-class SVM (FWOCSVM) model equals to the solution of the quadratic programming problem as follows:

$$
\begin{aligned}
& \min _{w, \mathcal{\varepsilon}, \rho} \frac{1}{2}\|w\|^{2}+\frac{1}{v l} \sum_{i=1}^{l} \xi_{i}-\rho \\
& \text { s.t. }\left\{\begin{array}{l}
\left(w \cdot \Phi\left(x_{i}\right)\right) \geq \rho-\xi_{i} \quad i=1,2, \ldots, l . \\
\xi_{i} \geq 0
\end{array}\right.
\end{aligned}
$$

This constrained optimization problem is dealt with by introducing Lagrange multipliers $\alpha, \beta \geq 0$ and a Lagrangian:

$$
\begin{aligned}
L(w, \varepsilon, \rho, \alpha, \beta)= & \frac{1}{2}\|w\|^{2}+\frac{1}{v l} \sum_{i=1}^{l} \xi_{i}-\rho \\
& -\sum_{i=1}^{l} \alpha_{i}\left(\left(w \cdot \Phi\left(x_{i}\right)\right)-\rho+\varepsilon_{i}\right)-\sum_{i=1}^{l} \beta_{i} \xi_{i} .
\end{aligned}
$$

After taking the partial derivatives with respect to $w$ and $\xi_{i}$, we will have the following formulas:

$$
\begin{gathered}
w=\sum_{i} \alpha_{i} \Phi\left(x_{i}\right), \\
\alpha_{i}=\frac{1}{v l}-\beta_{i} \leq \frac{1}{v l}, \quad \sum_{i} \alpha_{i}=1 .
\end{gathered}
$$

By substituting (20) into (18), it arrives at the dual problem of (18):

$$
\begin{aligned}
& \min _{\alpha} \frac{1}{2} \sum_{i=1}^{l} \sum_{j=1}^{l} \alpha_{i}\left\langle\Phi\left(x_{i}\right)^{T}, \Phi\left(x_{j}\right)\right\rangle \alpha_{j} \\
& \text { s.t. }\left\{\begin{array}{l}
0 \leq \alpha_{i} \leq \frac{1}{v l} \\
\sum_{i=1}^{l} \alpha_{i}=1
\end{array}\right.
\end{aligned}
$$

We employ the kernel function representation of $\left\langle\Phi\left(x_{i}\right)^{T}, \Phi\left(x_{j}\right)\right\rangle$, which is $K\left(x_{j}, x_{i}\right)=\left\langle\Phi\left(x_{i}\right)^{T}, \Phi\left(x_{j}\right)\right\rangle$. Then, the dual problem becomes

$$
\begin{aligned}
& \min _{\alpha} \frac{1}{2} \sum_{i=1}^{l} \sum_{j=1}^{l} \alpha_{i} \alpha_{j} K\left(x_{j}, x_{i}\right) \\
& \text { s.t. }\left\{\begin{array}{l}
0 \leq \alpha_{i} \leq \frac{1}{v l} \\
\sum_{i=1}^{l} \alpha_{i}=1
\end{array} \quad i=1,2, \ldots, l .\right.
\end{aligned}
$$

By solving problem (22), the final decision function $f(x)=\operatorname{sgn}\left(\sum_{i=1}^{l} \alpha_{i}^{*} K\left(x_{i}, x\right)-\rho^{*}\right)$ is obtained, representing the optimal hyperplane used to classify the samples. Finally, the BWH-FWOCSVM is constructed by substituting (17) into (22). Thus, the corresponding decision function is

$$
\begin{aligned}
f(x)=\operatorname{sgn}( & \left.\sum_{i=1}^{l} \alpha_{i}^{*} K_{\mathrm{MP}}\left(x, x^{\prime}\right)-\rho^{*}\right) \\
=\operatorname{sgn}( & \sum_{i=1}^{l} \alpha_{i}^{*} \rho K_{1}\left(x^{T} P, x_{i}^{T} P\right) \\
& \left.+(1-\rho) K_{2}\left(x^{T} P, x_{i}^{T} P\right)-\rho^{*}\right) .
\end{aligned}
$$


TABLE 1: The financial indicators.

\begin{tabular}{ll}
\hline Category & Indicators \\
\hline Liquidity & $\begin{array}{l}\text { Liquidity ratio (LR), quick ratio (QR), inventory turnover (IT), accounts receivable turnover (ART), current } \\
\text { assets turnover (CAT), total assets turnover (TAT) }\end{array}$ \\
\hline Debt paying ability & $\begin{array}{l}\text { Current asset ratio (CAR), current debt ratio (CDR), cash ratio (CR), asset-liability ratio (ALR), equity ratio } \\
\text { (ER), owner's equity ratio (OER) }\end{array}$ \\
\hline Profitability & $\begin{array}{l}\text { Return on equity (ROE), growth rate of return on equity (GRROE), rate of return on total assets (RRTA), return } \\
\text { on assets (ROA), growth rate of total assets (GRTA), operating profit ratio (OPR), growth rate of operating } \\
\text { profit (GROP), net profit growth rate (NPGR) }\end{array}$ \\
\hline Market value & $\begin{array}{l}\text { Earnings per share (EPS), net asset value per share (NAVPS), operating earnings per share (OEPS), price } \\
\text { earnings ratio (PER), price to book ratio (PBR), price-to-sales ratio (PSR), Tobin's Q (TQ), capital preservation } \\
\text { increment rate (CPIR) }\end{array}$ \\
\hline
\end{tabular}

\section{Empirical Experiment}

5.1. The Dataset and Indicators. In order to verify the performance of the BWH-FWOCSVM in financial distress prediction, the listed companies on Growth Enterprise Market (GEM) in China are selected as samples. A company is regarded as distressed if its EVA is negative and normal if its EVA is positive. A total of 284 companies listed on the GEM in 2012 are selected randomly as initial date set.

According to (8) (12), the EVAs of the selected 284 companies are calculated with the 3 5 years benchmark lending rate representing $K_{D}$ and other related data from the audited financial statements of those companies. Forty four companies with negative EVAs are regarded as distressed, while 240 with positive EVAs are regarded as normal. The ratio of distressed companies to normal ones is approximately $1: 5$ indicating obvious imbalance, which means one-class SVM is appropriate. The date set is split into the testing set and the training set, of which the former consists of 20 distressed companies and 100 normal companies (based on the ratio 1:5), and the latter includes the rest 164 companies. The EVAs of samples in every quarter of 2012 are calculated. Data in quarter $T-2$ is used to predict financial situations of companies in quarter $T$, which can avoid overestimating the prediction accuracy of the model.

Financial indicators have been consulted by researchers as a major basis for predicting financial distress and business crises [41]. Different financial indicators may cause different prediction results. Most of the financial indicators include inventory turnover, current asset ratio, earnings per share, net profit growth rate, and return on equity.[13, 42]. According to the particularity of China's securities market and the accounting system, financial indicators can be divided into different categories, such as liquidity, debt paying ability, profitability, and market value, and each category contains multiple relevant indicators $[43,44]$. In order to comprehensively summarize the financial situation of companies, a total of 28 financial ratios from four categories including liquidity, debt paying ability, profitability, and market value are selected as the initial indicators as listed in Table 1 . The GRDs between financial indicators and EVA are calculated and the results are listed in Table 2.

As Table 2 shows, there are significant differences among the GRDs, in which 8 GRDs are higher than 0.9 , and half of all the GRDs range between 0.7 and 0.8 . The results indicate
TABLE 2: The GRDs between financial indicators and EVA.

\begin{tabular}{lcccc}
\hline & Indicators & GRDs & Indicators & GRDs \\
\hline & IT & 0.995 & RRNA & 0.927 \\
$0.9 \leq$ GRD $\leq 1$ & GROP & 0.994 & NPGR & 0.917 \\
& ART & 0.969 & QR & 0.915 \\
& CA & 0.932 & LR & 0.907 \\
\hline \multirow{3}{*}{$0.8 \leq$ GRD $<0.9$} & GRTA & 0.889 & CDR & 0.809 \\
& PER & 0.881 & OER & 0.802 \\
& ER & 0.834 & & \\
\hline & CPIR & 0.799 & OEPS & 0.784 \\
& NAVPS & 0.799 & OPR & 0.784 \\
& CAR & 0.799 & CAT & 0.783 \\
& ALR & 0.797 & RRTA & 0.780 \\
& TQ & 0.794 & ROA & 0.778 \\
& TAT & 0.788 & ROE & 0.777 \\
& PBR & 0.785 & PSR & 0.769 \\
& EPS & 0.784 & & \\
\hline
\end{tabular}

that the relations between different indicators and financial situation are quite different. In this study, the corresponding GRD is regarded as the weight of the financial indicator.

5.2. Experiment Results and Analysis. In the past research, a variety of measurements are used to assess the prediction performance of the SVM in financial distress prediction. This study considers the following measurements:

(a) $P(D / D)$ : percentage of financial distressed companies predicted as distressed,

(b) $P(D / N)$ : percentage of normal companies predicted as distressed,

(c) Correct classification rate (CCR): percentage of companies predicted correctly in all companies.

Overall the CCR measures the prediction accuracy of the model, while $P(D / D)$ and $P(D / N)$ provide auxiliary discrimination. As we know, different types of misclassifications result in different penalty costs, for example, misclassifying a distressed company as a normal company may cause more damage than misclassifying a normal company as a distressed one. So the model with higher $P(D / D)$ is preferred if different models have the same or similar CCRs. 
TABLE 3: Results of BWH-FWOCSVM and BWH-OCSVM.

\begin{tabular}{|c|c|c|c|c|c|c|c|}
\hline \multirow{2}{*}{$\rho$} & \multirow{2}{*}{ Indicators } & \multicolumn{3}{|c|}{ BWH-FWOCSVM } & \multicolumn{3}{|c|}{ BWH-OCSVM } \\
\hline & & $C_{28}$ & $C_{13}$ & $C_{8}$ & $C_{28}$ & $C_{13}$ & $C_{8}$ \\
\hline \multirow{3}{*}{0} & CCR & $79.2 \%$ & $80.0 \%$ & $78.3 \%$ & $77.3 \%$ & $78.2 \%$ & $76.5 \%$ \\
\hline & $P(\mathrm{D} / \mathrm{D})$ & $71.5 \%$ & $74.1 \%$ & $70.1 \%$ & $70.4 \%$ & $72.5 \%$ & $69.6 \%$ \\
\hline & $P(\mathrm{D} / \mathrm{N})$ & $19.2 \%$ & $18.8 \%$ & $19.7 \%$ & $20.2 \%$ & $19.4 \%$ & $20.9 \%$ \\
\hline \multirow{3}{*}{0.1} & CCR & $80.9 \%$ & $81.7 \%$ & $79.2 \%$ & $79.2 \%$ & $80.0 \%$ & $78.3 \%$ \\
\hline & $P(\mathrm{D} / \mathrm{D})$ & $72.5 \%$ & $75.1 \%$ & $71.6 \%$ & $71.4 \%$ & $73.9 \%$ & $70.6 \%$ \\
\hline & $P(\mathrm{D} / \mathrm{N})$ & $17.4 \%$ & $17.0 \%$ & $19.0 \%$ & $19.5 \%$ & $18.7 \%$ & $20.1 \%$ \\
\hline \multirow{3}{*}{0.2} & CCR & $81.7 \%$ & $85.0 \%$ & $80.1 \%$ & $79.3 \%$ & $80.8 \%$ & $78.3 \%$ \\
\hline & $P(\mathrm{D} / \mathrm{D})$ & $72.5 \%$ & $78.2 \%$ & $73.9 \%$ & $71.4 \%$ & $74.9 \%$ & $71.1 \%$ \\
\hline & $P(\mathrm{D} / \mathrm{N})$ & $16.4 \%$ & $13.7 \%$ & $18.5 \%$ & $19.5 \%$ & $17.7 \%$ & $20.2 \%$ \\
\hline \multirow{3}{*}{0.3} & CCR & $82.5 \%$ & $85.0 \%$ & $80.0 \%$ & $79.3 \%$ & $81.7 \%$ & $79.0 \%$ \\
\hline & $P(\mathrm{D} / \mathrm{D})$ & $77.8 \%$ & $78.7 \%$ & $74.9 \%$ & $72.4 \%$ & $74.9 \%$ & $71.1 \%$ \\
\hline & $P(\mathrm{D} / \mathrm{N})$ & $16.5 \%$ & $13.8 \%$ & $18.7 \%$ & $19.2 \%$ & $16.9 \%$ & $19.2 \%$ \\
\hline \multirow{3}{*}{0.4} & CCR & $81.8 \%$ & $84.2 \%$ & $81.7 \%$ & $80.8 \%$ & $82.5 \%$ & $79.2 \%$ \\
\hline & $P(\mathrm{D} / \mathrm{D})$ & $79.2 \%$ & $83.2 \%$ & $77.7 \%$ & $74.3 \%$ & $75.4 \%$ & $73.0 \%$ \\
\hline & $P(\mathrm{D} / \mathrm{N})$ & $17.8 \%$ & $15.7 \%$ & $17.3 \%$ & $18.8 \%$ & $16.0 \%$ & $19.6 \%$ \\
\hline \multirow{3}{*}{0.5} & CCR & $82.5 \%$ & $84.2 \%$ & $83.3 \%$ & $81.5 \%$ & $83.3 \%$ & $80.8 \%$ \\
\hline & $P(\mathrm{D} / \mathrm{D})$ & $80.7 \%$ & $84.8 \%$ & $77.8 \%$ & $75.3 \%$ & $76.3 \%$ & $75.0 \%$ \\
\hline & $P(\mathrm{D} / \mathrm{N})$ & $17.1 \%$ & $16.0 \%$ & $15.3 \%$ & $17.8 \%$ & $16.2 \%$ & $18.0 \%$ \\
\hline \multirow{3}{*}{0.6} & CCR & $84.2 \%$ & $86.7 \%$ & $82.5 \%$ & $83.3 \%$ & $83.3 \%$ & $81.5 \%$ \\
\hline & $P(\mathrm{D} / \mathrm{D})$ & $80.8 \%$ & $84.8 \%$ & $79.1 \%$ & $77.6 \%$ & $80.2 \%$ & $75.5 \%$ \\
\hline & $P(\mathrm{D} / \mathrm{N})$ & $15.1 \%$ & $13.0 \%$ & $16.6 \%$ & $15.5 \%$ & $16.0 \%$ & $17.1 \%$ \\
\hline \multirow{3}{*}{0.7} & CCR & $85.0 \%$ & $90.0 \%$ & $85.8 \%$ & $84.0 \%$ & $84.2 \%$ & $83.3 \%$ \\
\hline & $P(\mathrm{D} / \mathrm{D})$ & $82.1 \%$ & $91.4 \%$ & $83.9 \%$ & $81.4 \%$ & $82.1 \%$ & $78.9 \%$ \\
\hline & $P(\mathrm{D} / \mathrm{N})$ & $14.4 \%$ & $10.3 \%$ & $13.6 \%$ & $15.2 \%$ & $15.4 \%$ & $15.8 \%$ \\
\hline \multirow{3}{*}{0.8} & CCR & $87.5 \%$ & $87.5 \%$ & $83.3 \%$ & $84.3 \%$ & $85.8 \%$ & $82.2 \%$ \\
\hline & $P(\mathrm{D} / \mathrm{D})$ & $81.3 \%$ & $86.3 \%$ & $79.6 \%$ & $79.5 \%$ & $79.7 \%$ & $75.5 \%$ \\
\hline & $P(\mathrm{D} / \mathrm{N})$ & $11.2 \%$ & $12.3 \%$ & $15.7 \%$ & $15.9 \%$ & $12.9 \%$ & $15.9 \%$ \\
\hline \multirow{3}{*}{0.9} & CCR & $82.5 \%$ & $83.3 \%$ & $81.7 \%$ & $80.8 \%$ & $81.7 \%$ & $80.0 \%$ \\
\hline & $P(\mathrm{D} / \mathrm{D})$ & $81.2 \%$ & $80.2 \%$ & $77.3 \%$ & $77.6 \%$ & $78.7 \%$ & $73.0 \%$ \\
\hline & $P(\mathrm{D} / \mathrm{N})$ & $17.2 \%$ & $16.1 \%$ & $17.2 \%$ & $18.5 \%$ & $17.7 \%$ & $18.6 \%$ \\
\hline \multirow{3}{*}{1} & CCR & $82.6 \%$ & $84.2 \%$ & $81.7 \%$ & $80.8 \%$ & $82.5 \%$ & $80.0 \%$ \\
\hline & $P(\mathrm{D} / \mathrm{D})$ & $77.3 \%$ & $80.7 \%$ & $77.3 \%$ & $75.2 \%$ & $77.3 \%$ & $73.5 \%$ \\
\hline & $P(\mathrm{D} / \mathrm{N})$ & $16.4 \%$ & $15.2 \%$ & $17.2 \%$ & $18.0 \%$ & $16.4 \%$ & $18.7 \%$ \\
\hline
\end{tabular}

Three financial indicator sets are constructed for the experiment, which consist of 28 indicators $\left(C_{28}\right), 13$ indicators $\left(C_{13}\right)$, and 8 indicators $\left(C_{8}\right)$ corresponding to $\mathrm{GRD} \geq 0.7$, $\mathrm{GRD} \geq 0.8$, and GRD $\geq 0.9$, respectively. Because the weight coefficient $\rho$ in hybrid kernel function have influence on the prediction accuracy, we use grid search method to analyze the influence of $\rho$, when the search step length is 0.1 . When $\rho=0$, the kernel function is a linear kernel function; when $\rho=1$, the kernel function represents the CDF9/7 biorthogonal wavelet kernel function. The corresponding results are displayed in Table 3 and Figures 1 and 2. The results of nonweighted OCSVM based on biorthogonal wavelet hybrid kernel function (BWH-OCSVM) are also given for comparison. Penalty parameter $C$ and insensitive parameter $\varepsilon$ are two parameters which have great influence on performance of SVMs. Many optimization methods have been introduced, and particle swarm optimization (PSO) algorithm [29] is applied in this study to obtain the optimal $C$ and $\varepsilon$.

Figures 1 and 2 and Table 3 illustrate that the relation is nonlinear between the prediction accuracy of the model and the number of financial indicators. No matter in the $\mathrm{BWH}$ FWOCSVM or in the BWH-OCSVM, $C_{8}$ almost always provides the lowest CCR while $C_{13}$ almost always has the highest one, and the CCRs of $C_{28}$ is in between roughly. The results of $P(D / D)$ and $P(D / N)$ are also similar. The results demonstrate that few financial indicators are selected if the threshold of the GRD is too high, which may lead to information loss and accuracy decrease. On the other hand, the low threshold of the GRD gives rise to too many financial indicators, which may also affect the prediction accuracy because of information redundancy. As the financial indicator set depends on the threshold of the GRD, how 


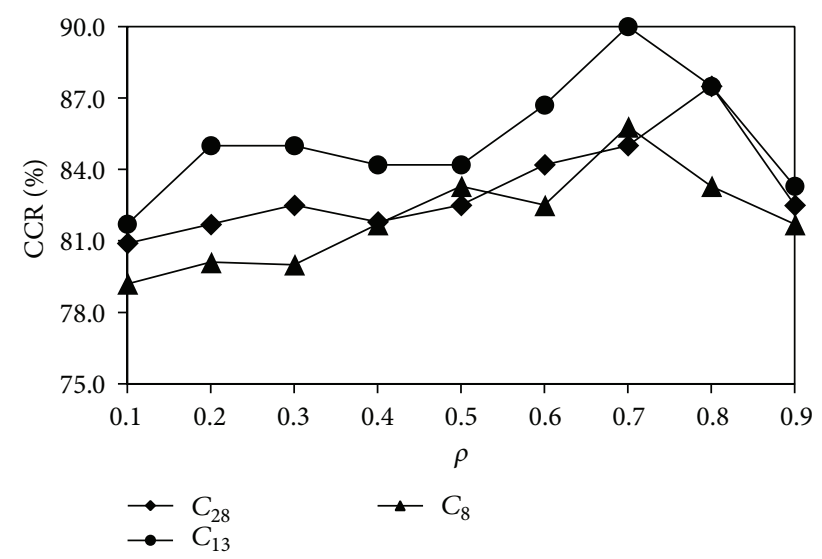

Figure 1: CCRs of BWH-FWOCSVM.

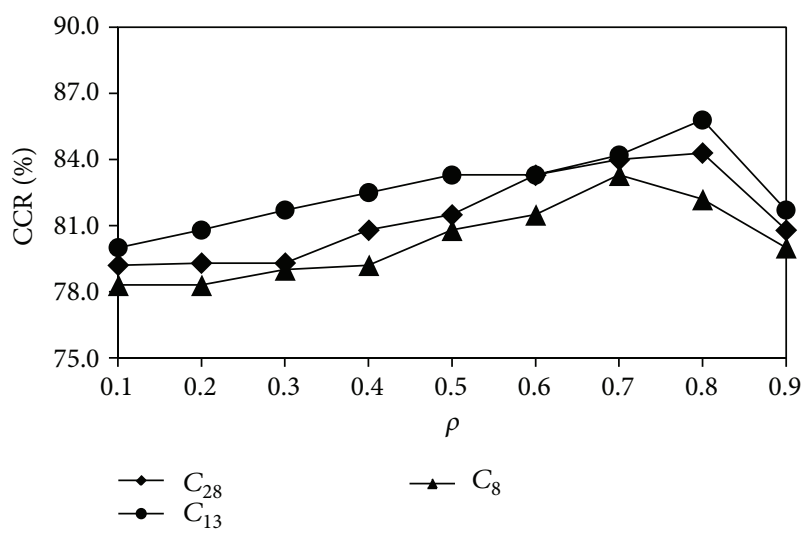

FIgure 2: CCRs of BWH-OCSVM.

to determine the proper threshold value is important to the financial distress prediction. In fact, how to select an appropriate financial indicator set is still an open issue [31].

As shown in Figures 1 and 2, with the increase of $\rho$, the CCRs of the BWH-FWOCSVM and the CCRs of the BWHOCSVM rise at first but fall later, whether it is for $C_{28}, C_{13}$, or $C_{8}$. The highest CCR can be reached when $\rho \in[0.7,0.8]$. The results in Figures 3 and 4 conduct the comparison of CCRs between hybrid kernel, linear kernel (LK), and CDF9/7 biorthogonal wavelet kernel (Cdf9/7 BWK). The H-BWHK refers to the highest CCR of the SVM based on biorthogonal wavelet hybrid kernel, while the A-BWHK refers to the average of nine CCRs when $\rho$ changes from 0.1 to 0.9. For both the BWH-FWOCSVM and the BWH-OCSVM with indicator sets $C_{28}, C_{13}$, and $C_{8}$, the A-BWHK is higher than the CCR of LK and Cdf9/7 BWK, and the H-BWHK has more obvious advantage. Nevertheless, the selection of $\rho$ has a great impact on the prediction accuracy. An inappropriate $\rho$ may lead to the consequence that the prediction accuracy of a hybrid kernel function SVM model is lower than that of the single kernel SVM model. In fact, besides grid search method, optimal algorithm such as PSO and genetic algorithm can also be a substitution.

In Table 3, it is obvious that weighting the financial indicators based on the EVA and the GRA can improve

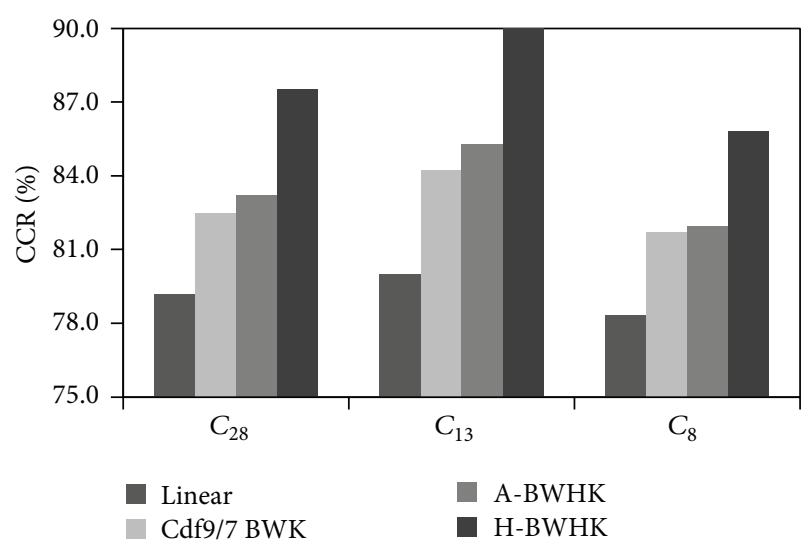

FIGURE 3: CCRs of BWH-FWOCSVM based-on single and hybrid kernels.

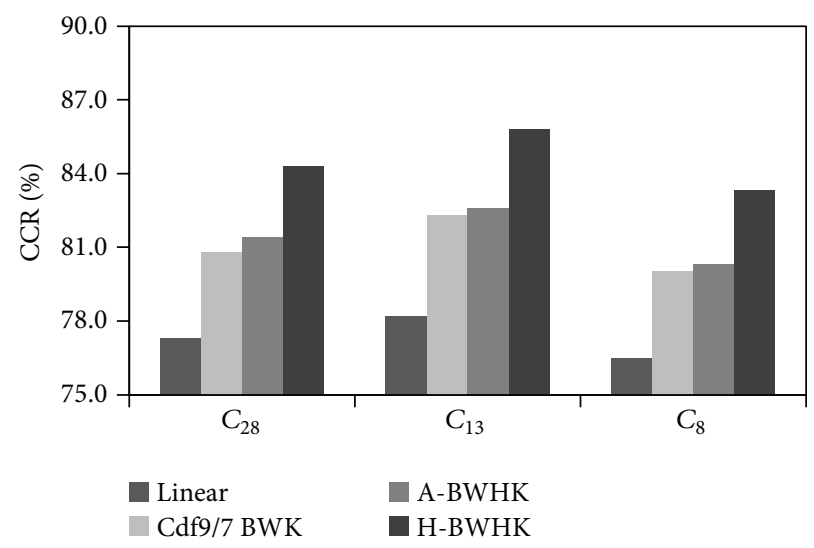

FIgURE 4: CCRs of BWH-OCSVM based-on single and hybrid kernels.

the prediction accuracy effectively. Considering the average value on the eleven cases when $\rho$ ranges from 0 to 1 , CCRs of the BWH-FWOCSVM are $1.8 \%, 2.5 \%$, and $1.7 \%$ higher than those of the BWH-OCSVM, respectively, with $C_{28}$, $C_{13}$, and $C_{8}$, while the $P(D / D)$ s of the BWH-FWOCSVM are $2.8 \%, 2.5 \%$, and $1.7 \%$ higher than those of the BWHOCSVM, respectively. Considering the CCR as a selection criteria, $P(D / D)$ and $P(D / N)$ of the BWH-FWOCSVM and the BWH-OCSVM with the highest CCR are selected for comparison (i.e., both of the two models with highest CCR satisfy the following conditions: the indicator set is $C_{13}$ and $\rho=0.7)$. We can find that the BWH-FWOCSVM has more advantage specifically, $P(D / D)$ and $P(D / N)$ are, respectively, 9.3\% higher and 5.1\% lower than those of the BWH-OCSVM. Given that $P(D / D)$ indicates the model's effectiveness in classifying the financial distressed companies correctly, and misclassifying a financial distressed company as a normal one may cause huge risk, the BWH-FWOCSVM is more effective than nonweighted BWH-OCSVM in financial distress prediction.

The statistical significance of the difference between the BWH-FWOCSVM and the BWH-OCSVM on the CCR is assessed by using the Wilcoxon signed ranks test. Wilcoxon 
TABLE 4: Wilcoxon test of CCRs between BWH-FWOCSVM and BWH-OCSVM.

\begin{tabular}{lccc}
\hline Test statistics & \multicolumn{3}{c}{ OCSVM-FWOCSVM } \\
& $C_{28}$ & $C_{13}$ & $C_{8}$ \\
\hline$Z$ & -2.943 & -2.949 & -2.944 \\
$\alpha$ & 0.003 & 0.003 & 0.003 \\
\hline
\end{tabular}

test is a nonparametric test method and applied when overall distribution is unknown [45]. For the CCR in Table 3, the results of Wilcoxon test are shown in Table 4 . The value of $Z$ statistics of $C_{28}, C_{13}$, and $C_{8}$ are $-2.943,-2.949$, and -2.944 , respectively. Concomitant probability $\alpha$ of three financial indicator sets are all 0.003, less than the significance level of 0.01 , which indicates the CCRs of BWH-FWOCSVM are higher than those of the BWH-OCSVM in the significance level of 0.01 .

Many researches demonstrate that the SVM is superior to the DA, logistic regression, and ANNs in financial distress prediction, so similar comparisons will not be conducted in this study. In order to verify the performance of the proposed CDF9/7 biorthogonal wavelet kernel and hybrid kernel function $K_{M}$, we compare the two kinds of kernel functions with the other five single kernel functions, including Poly kernel, Sigmoid kernel, RBF kernel, Morlet kernel, and Coif3 kernel, as shown in Table 5.

From Table 5 we can conclude that biorthogonal wavelet hybrid kernel $K_{M}$ has the best performance in both the FWOCSVM and the OCSVM. No matter which indicator set is used, SVM models based on $K_{M}$ get higher CCRs, higher $P(D / D)$ s and lower $P(D / N)$ s than other single kernel functions. Taking the FWOCSVM as an example, the CCRs of $K_{M}$ are, respectively, $7.3 \%, 8.3 \%$, and $6.7 \%$ higher than the average CCR of the other five single kernels with $C_{28}, C_{13}$, and $C_{8}$, while $P(D / D)$ s of $K_{M}$ are $6.4 \%, 14.1 \%$, and $11.4 \%$ higher. Also, the results illustrate that the proposed Cdf9/7 biorthogonal wavelet kernel outperforms the above five single kernels overall in CCR, $P(D / D)$, and $P(D / N)$, only with the exception of $0.5 \% P(D / D)$ lower than the Coif3 in the FWOCSVM with $C_{13}$.

For the SVMs based on same kernel, the FWOCSVM has higher CCR, higher $P(D / D)$, and lower $P(D / N)$. For instance, in Figures 5 and 6 with $C_{13}$, the average CCR of the FWOCSVM based on eight different kernels is $2.5 \%$ higher than the OCSVM, and the maximum value of CCR is $4.2 \%$ higher. Meanwhile, the average $P(D / D)$ is $4 \%$ higher and the maximum value of $P(D / D)$ is $11.7 \%$ higher. It also proves that weighting the financial indicators based on the GRA and the EVA improves the accuracy of the financial distress prediction effectively. The statistical significance of the difference on the CCR between the FWOCSVM and the OCSVM based on different kernels is also assessed by using the Wilcoxon test and the results are shown in Table 6. The value of $Z$ statistics of $C_{28}, C_{13}$, and $C_{8}$ are -2.521 , -2.524 , and -2.524 , respectively. Concomitant probability $\alpha$ of three financial indicator sets are all 0.012, smaller than the significance level of 0.05 , which indicates the CCRs of

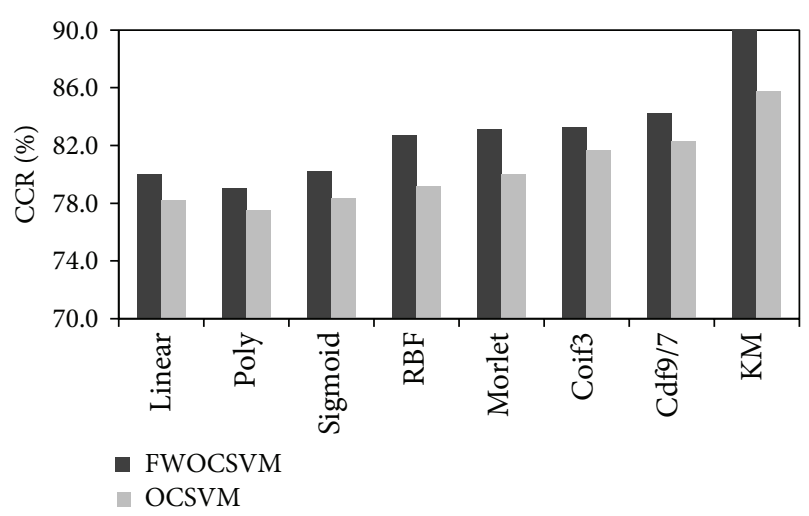

FIgURE 5: CCRs based on different kernels with set $C_{13}$.

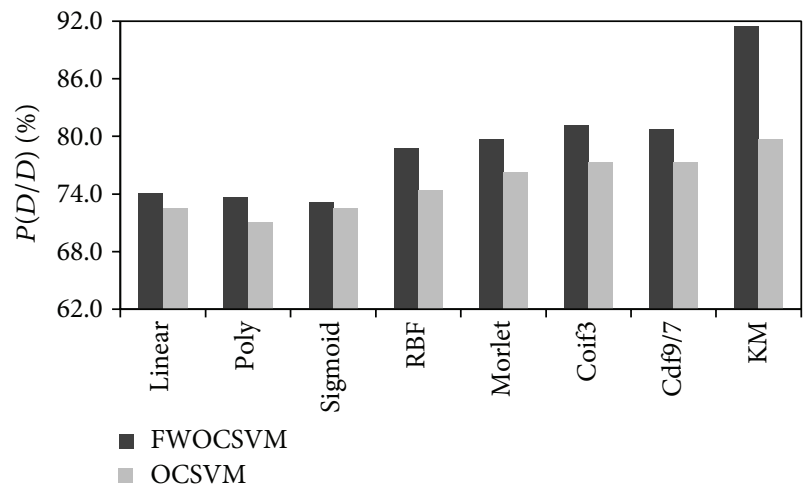

Figure 6: $P(D / D)$ s based on different kernels with set $C_{13}$.

the FWOCSVM based on different kernels are higher than those of the BWH-OCSVM in the significance level of 0.05 .

\section{Conclusion}

In this paper, we develop and implement a framework of a financial distress prediction model based on publicly available data. To this end, a novel biorthogonal wavelet hybrid kernel function is constructed by combining linear kernel function with biorthogonal wavelet kernel function, and a new feature weighted approach based on the EVA and the GRA is presented. The novel biorthogonal wavelet hybrid kernel function takes full advantage of different kernel functions' mapping abilities and has good learning performance, while the new feature weighted approach is applied to weight financial indicators. Considering the imbalance between financially distressed companies and normal ones, the feature weighted one-class SVM based on the biorthogonal wavelet hybrid kernel (BWH-FWOCSVM) is further proposed and the empirical analysis conducted on the 284 listed companies in the GEM of China shows good performance of the proposed approach. The financial distress prediction model proposed in this paper is a reliable and feasible system for evaluating financial situation of the listed companies. 
TABLE 5: Results of FWOCSVM and OCSVM based on different kernels.

\begin{tabular}{|c|c|c|c|c|c|c|c|}
\hline \multirow{2}{*}{ Indicator set } & \multirow{2}{*}{ Kernel function } & \multicolumn{3}{|c|}{ FWOCSVM } & \multicolumn{3}{|c|}{ OCSVM } \\
\hline & & CCR & $P(\mathrm{D} / \mathrm{D})$ & $P(\mathrm{D} / \mathrm{N})$ & CCR & $P(\mathrm{D} / \mathrm{D})$ & $P(\mathrm{D} / \mathrm{N})$ \\
\hline \multirow{8}{*}{$C_{28}$} & Linear & $79.2 \%$ & $71.5 \%$ & $19.2 \%$ & $77.3 \%$ & $70.4 \%$ & $20.2 \%$ \\
\hline & Poly & $78.3 \%$ & $71.5 \%$ & $20.5 \%$ & $76.7 \%$ & $68.7 \%$ & $21.5 \%$ \\
\hline & Sigmoid & $79.3 \%$ & $72.0 \%$ & $20.2 \%$ & $77.5 \%$ & $70.8 \%$ & $21.0 \%$ \\
\hline & $\mathrm{RBF}$ & $80.8 \%$ & $76.3 \%$ & $18.5 \%$ & $77.8 \%$ & $71.5 \%$ & $20.2 \%$ \\
\hline & Morlet & $80.8 \%$ & $76.8 \%$ & $18.4 \%$ & $78.8 \%$ & $73.3 \%$ & $19.6 \%$ \\
\hline & Coif3 & $81.7 \%$ & $77.2 \%$ & $17.6 \%$ & $80.5 \%$ & $74.3 \%$ & $18.8 \%$ \\
\hline & Cdf9/7 & $82.5 \%$ & $77.3 \%$ & $16.4 \%$ & $80.8 \%$ & $75.2 \%$ & $18.0 \%$ \\
\hline & $K_{M}$ & $87.5 \%$ & $81.2 \%$ & $11.2 \%$ & $84.3 \%$ & $79.5 \%$ & $15.9 \%$ \\
\hline \multirow{8}{*}{$C_{13}$} & Linear & $80.0 \%$ & $74.1 \%$ & $18.8 \%$ & $78.2 \%$ & $72.5 \%$ & $19.9 \%$ \\
\hline & Poly & $79.0 \%$ & $73.6 \%$ & $18.7 \%$ & $77.5 \%$ & $71.0 \%$ & $21.1 \%$ \\
\hline & Sigmoid & $80.2 \%$ & $73.1 \%$ & $18.6 \%$ & $78.3 \%$ & $72.5 \%$ & $20.4 \%$ \\
\hline & RBF & $82.7 \%$ & $78.7 \%$ & $16.7 \%$ & $79.2 \%$ & $74.4 \%$ & $19.8 \%$ \\
\hline & Morlet & $83.1 \%$ & $79.7 \%$ & $16.0 \%$ & $80.0 \%$ & $76.3 \%$ & $19.2 \%$ \\
\hline & Coif3 & $83.3 \%$ & $81.2 \%$ & $16.2 \%$ & $81.7 \%$ & $77.3 \%$ & $17.4 \%$ \\
\hline & Cdf9/7 & $84.2 \%$ & $80.7 \%$ & $15.2 \%$ & $82.3 \%$ & $77.3 \%$ & $16.7 \%$ \\
\hline & $K_{M}$ & $90.0 \%$ & $91.4 \%$ & $10.3 \%$ & $85.8 \%$ & $79.7 \%$ & $12.9 \%$ \\
\hline \multirow{8}{*}{$C_{8}$} & Linear & $78.3 \%$ & $70.1 \%$ & $19.7 \%$ & $76.5 \%$ & $69.6 \%$ & $22.1 \%$ \\
\hline & Poly & $77.5 \%$ & $69.1 \%$ & $22.1 \%$ & $75.8 \%$ & $67.6 \%$ & $22.5 \%$ \\
\hline & Sigmoid & $77.7 \%$ & $69.7 \%$ & $21.4 \%$ & $76.7 \%$ & $70.1 \%$ & $22.0 \%$ \\
\hline & RBF & $80.2 \%$ & $73.0 \%$ & $19.7 \%$ & $77.5 \%$ & $71.1 \%$ & $21.2 \%$ \\
\hline & Morlet & $79.5 \%$ & $74.9 \%$ & $19.1 \%$ & $78.3 \%$ & $72.1 \%$ & $20.4 \%$ \\
\hline & Coif3 & $80.8 \%$ & $75.8 \%$ & $17.9 \%$ & $79.2 \%$ & $73.0 \%$ & $19.6 \%$ \\
\hline & Cdf9/7 & $81.7 \%$ & $77.3 \%$ & $17.2 \%$ & $80.0 \%$ & $73.5 \%$ & $18.7 \%$ \\
\hline & $K_{M}$ & $85.8 \%$ & $83.9 \%$ & $13.6 \%$ & $83.3 \%$ & $78.9 \%$ & $15.8 \%$ \\
\hline
\end{tabular}

TABLE 6: Wilcoxon test of CCRs between FWOCSVM and OCSVM based on different kernels.

\begin{tabular}{lccc}
\hline Test statistics & \multicolumn{3}{c}{ OCSVM-FWOCSVM } \\
& $C_{28}$ & $C_{13}$ & $C_{8}$ \\
\hline$Z$ & -2.521 & -2.524 & -2.524 \\
$\alpha$ & 0.012 & 0.012 & 0.012 \\
\hline
\end{tabular}

However, in this study, the optimal weighting coefficient $\rho$ is obtained by the grid search method with the search step length 0.1 , which may not be precise enough. In further studies, other optimization methods such as genetic algorithm will be applied to obtain $\rho$ in hybrid kernel. Besides, linear combination of different kernels is applied in this paper and in further studies nonlinear combination of different kernels will be studied in financial distress prediction.

\section{Conflict of Interests}

The authors declare that there is no conflict of interests regarding the publication of this paper.

\section{Acknowledgment}

This research was supported by the NSFC grant (no. 71201024).

\section{References}

[1] J. K. Bae, "Predicting financial distress of the South Korean manufacturing industries," Expert Systems with Applications, vol. 39, no. 10, pp. 9159-9165, 2012.

[2] J. Sun, M.-Y. Jia, and H. Li, "AdaBoost ensemble for financial distress prediction: an empirical comparison with data from Chinese listed companies," Expert Systems with Applications, vol. 38, no. 8, pp. 9305-9312, 2011.

[3] H. Li and J. Sun, "Ranking-order case-based reasoning for financial distress prediction," Knowledge-Based Systems, vol. 21, no. 8, pp. 868-878, 2008.

[4] H. Li and J. Sun, "Empirical research of hybridizing principal component analysis with multivariate discriminant analysis and logistic regression for business failure prediction," Expert Systems with Applications, vol. 38, no. 5, pp. 6244-6253, 2011.

[5] K. J. M. Janssen, I. Siccama, Y. Vergouwe et al., "Development and validation of clinical prediction models: marginal differences between logistic regression, penalized maximum likelihood estimation, and genetic programming," Journal of Clinical Epidemiology, vol. 65, no. 4, pp. 404-412, 2012.

[6] B. M. Kibria and A. K. Saleh, "Improving the estimators of the parameters of a probit regression model: a ridge regression approach," Journal of Statistical Planning and Inference, vol. 142, no. 6, pp. 1421-1435, 2012.

[7] J. Sun and H. Li, "Financial distress prediction using support vector machines: ensemble vs. individual," Applied Soft Computing Journal, vol. 12, no. 8, pp. 2254-2265, 2012. 
[8] K.-S. Shin and Y.-J. Lee, "A genetic algorithm application in bankruptcy prediction modeling," Expert Systems with Applications, vol. 23, no. 3, pp. 321-328, 2002.

[9] A. I. Dimitras, R. Slowinski, R. Susmaga, and C. Zopounidis, "Business failure prediction using rough sets," European Journal of Operational Research, vol. 114, no. 2, pp. 263-280, 1999.

[10] H. Jo, I. Han, and H. Lee, "Bankruptcy prediction using casebased reasoning, neural networks, and discriminant analysis," Expert Systems with Applications, vol. 13, no. 2, pp. 97-108, 1997.

[11] A. F. Atiya, "Bankruptcy prediction for credit risk using neural networks: a survey and new results," IEEE Transactions on Neural Networks, vol. 12, no. 4, pp. 929-935, 2001.

[12] Z. Huang, H. Chen, C.-J. Hsu, W.-H. Chen, and S. Wu, "Credit rating analysis with support vector machines and neural networks: a market comparative study," Decision Support Systems, vol. 37, no. 4, pp. 543-558, 2004.

[13] K.-S. Shin, T. S. Lee, and H.-J. Kim, "An application of support vector machines in bankruptcy prediction model," Expert Systems with Applications, vol. 28, no. 1, pp. 127-135, 2005.

[14] W. Härdle, R. A. Moro, and D. Schäfer, Handbook of Data Visualization, Springer, New York, NY, USA, 2008.

[15] L. Zhang, W. Zhou, and L. Jiao, "Wavelet support vector machine," IEEE Transactions on Systems, Man, and Cybernetics Part B: Cybernetics, vol. 34, no. 1, pp. 34-39, 2004.

[16] C.-C. Wei, "Wavelet kernel support vector machines forecasting techniques: case study on water-level predictions during typhoons," Expert Systems with Applications, vol. 39, no. 5, pp. 5189-5199, 2012.

[17] M.-H. Yang and R.-C. Wang, "DDoS detection based on wavelet kernel support vector machine," The Journal of China Universities of Posts and Telecommunications, vol. 15, no. 3, pp. 59-63, 2008.

[18] M. Yogo, "Measuring business cycles: a wavelet analysis of economic time series," Economics Letters, vol. 100, no. 2, pp. 208-212, 2008.

[19] Y.-L. Lu, L. Li, M.-M. Zhou, and G.-L. Tian, "A new fuzzy support vector machine based on mixed kernel function," in Proceedings of the 8th International Conference on Machine Learning and Cybernetics, vol. 12-15, pp. 526-531, Baoding, China, July 2009.

[20] J. George and K. Rajeev, "Hybrid wavelet support vector regression," in Proceedings of the 7th IEEE International Conference on Cybernetic Intelligent Systems (CIS '08), pp. 1-6, September 2008.

[21] J. Li and S. Sun, "Nonlinear combination of multiple kernels for support vector machines," in Proceedings of the 20th International Conference on Pattern Recognition (ICPR '10), pp. 28892892, August 2010.

[22] C. Cortes, M. Mohri, and A. Rostamizadeh, "Learning nonlinear combinations of kernels," in Proceedings of the 23rd Annual Conference on Neural Information Processing Systems (NIPS '09), pp. 396-404, December 2009.

[23] J. Chai, H. Chen, L. Huang, and F. Shang, "Maximum margin multiple-instance feature weighting," Pattern Recognition, vol. 47, no. 6, pp. 2091-2103, 2014.

[24] S. J. Song, X. G. Zhao, J. Xie, and Y. Y. Guan, "Grey correlation analysis and regression estimation of mining subsidence in $\mathrm{Yu}-$ Shen-Fu mining area," in Proceedings of the 3rd International Conference on Environmental Science and Information Application Technology (ESIAT '11), vol. 10, pp. 1747-1752, August 2011.
[25] C.-Y. Kung and K.-L. Wen, "Applying grey relational analysis and grey decision-making to evaluate the relationship between company attributes and its financial performance-a case study of venture capital enterprises in Taiwan," Decision Support Systems, vol. 43, no. 3, pp. 842-852, 2007.

[26] S.-L. Lin and S.-J. Wu, "Is grey relational analysis superior to the conventional techniques in predicting financial crisis?" Expert Systems with Applications, vol. 38, no. 5, pp. 5119-5124, 2011.

[27] R.-H. Lin, Y.-T. Wang, C.-H. Wu, and C.-L. Chuang, "Developing a business failure prediction model via RST, GRA and CBR," Expert Systems with Applications, vol. 36, no. 2, pp. 1593-1600, 2009.

[28] C.-L. Chuang, "Application of hybrid case-based reasoning for enhanced performance in bankruptcy prediction," Information Sciences, vol. 236, pp. 174-185, 2013.

[29] M. Psillaki, I. E. Tsolas, and D. Margaritis, "Evaluation of credit risk based on firm performance," European Journal of Operational Research, vol. 201, no. 3, pp. 873-881, 2010.

[30] S. Piramuthu, "On preprocessing data for financial credit risk evaluation," Expert Systems with Applications, vol. 30, no. 3, pp. 489-497, 2006.

[31] Q. Liu and Z. Lu, "Corporate governance and earnings management in the Chinese listed companies: a tunneling perspective," Journal of Corporate Finance, vol. 13, no. 5, pp. 881-906, 2007.

[32] G. F. Smits and E. M. Jordaan, "Improved SVM regression using mixtures of kernels," in Proceedings of the International Joint Conference on Neural Networks (IJCNN '02), vol. 3, pp. 27852790, May 2002.

[33] C. Huang, L. L. Huang, and W. J. Zhong, "Chaotic time series forecasting based on Cdf9/7 biorthogonal wavelet kernel support vector machine," in Proceedings of the 7th International Conference on Natural Computation (ICNC '11), vol. 1, pp. 348352, July 2011.

[34] D. Young, "Economic value added: a primer for European managers," European Management Journal, vol. 15, no. 4, pp. 335-343, 1997.

[35] B. D. Tortella and S. Brusco, "The economic value added (EVA): an analysis of market reaction," Advances in Accounting, vol. 20, pp. 265-290, 2003.

[36] A. M. L. Destri, "Bringing strategy back into financial systems of performance measurement: integrating EVA and PBC," Business Systems Review, vol. 1, no. 1, pp. 85-102, 2012.

[37] J. de Villiers, "The distortions in Economic Value Added (EVA) caused by inflation," Journal of Economics and Business, vol. 49, no. 3, pp. 285-300, 1997.

[38] L. M. Lovata and M. L. Costigan, "Empirical analysis of adopters of economic value added," Management Accounting Research, vol. 13, no. 2, pp. 215-228, 2002.

[39] H. Wong, B. Q. Hu, W. C. Ip, and J. Xia, "Change-point analysis of hydrological time series using grey relational method," Journal of Hydrology, vol. 324, no. 1-4, pp. 323-338, 2006.

[40] B. Schölkopf, J. C. Platt, J. Shawe-Taylor, A. J. Smola, and R. C. Williamson, "Estimating the support of a high-dimensional distribution," Neural Computation, vol. 13, no. 7, pp. 1443-1471, 2001.

[41] F. Lin, D. Liang, and E. Chen, "Financial ratio selection for business crisis prediction," Expert Systems with Applications, vol. 38, no. 12, pp. 15094-15102, 2011.

[42] S.-H. Min, J. Lee, and I. Han, "Hybrid genetic algorithms and support vector machines for bankruptcy prediction," Expert Systems with Applications, vol. 31, no. 3, pp. 652-660, 2006. 
[43] S. Y. Kim and A. Upneja, "Predicting restaurant financial distress using decision tree and AdaBoosted decision tree models," Economic Modelling, vol. 36, no. 1, pp. 354-362, 2014.

[44] Y.-S. Chen and C.-H. Cheng, "Hybrid models based on rough set classifiers for setting credit rating decision rules in the global banking industry," Knowledge-Based Systems, vol. 39, no. 2, pp. 224-239, 2013.

[45] D. C. Montgomery and G. C. Runger, Applied Statistics and Probability for Engineers, Wiley, 4th edition, 2006. 


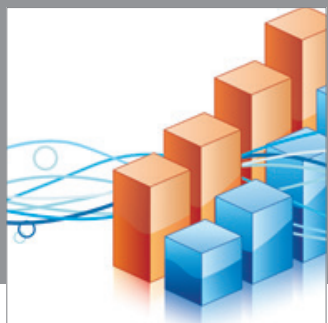

Advances in

Operations Research

mansans

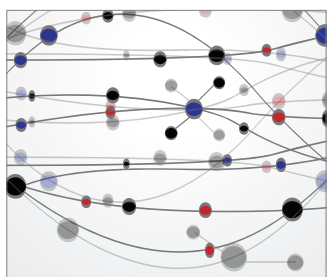

The Scientific World Journal
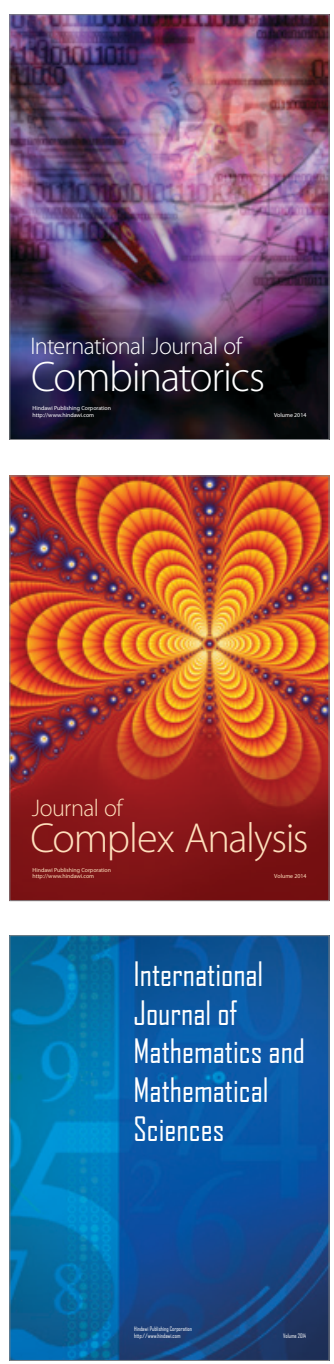
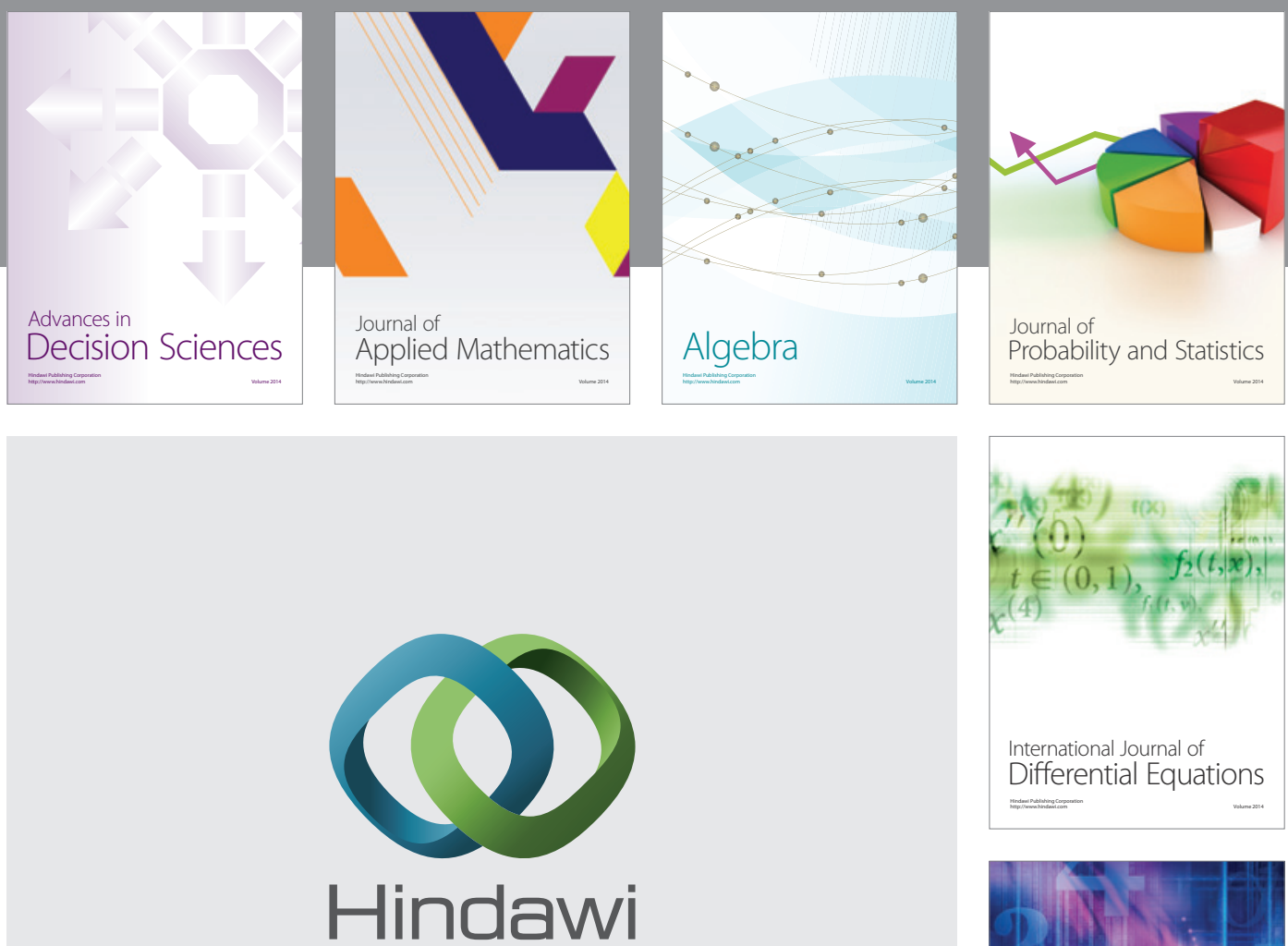

Submit your manuscripts at http://www.hindawi.com
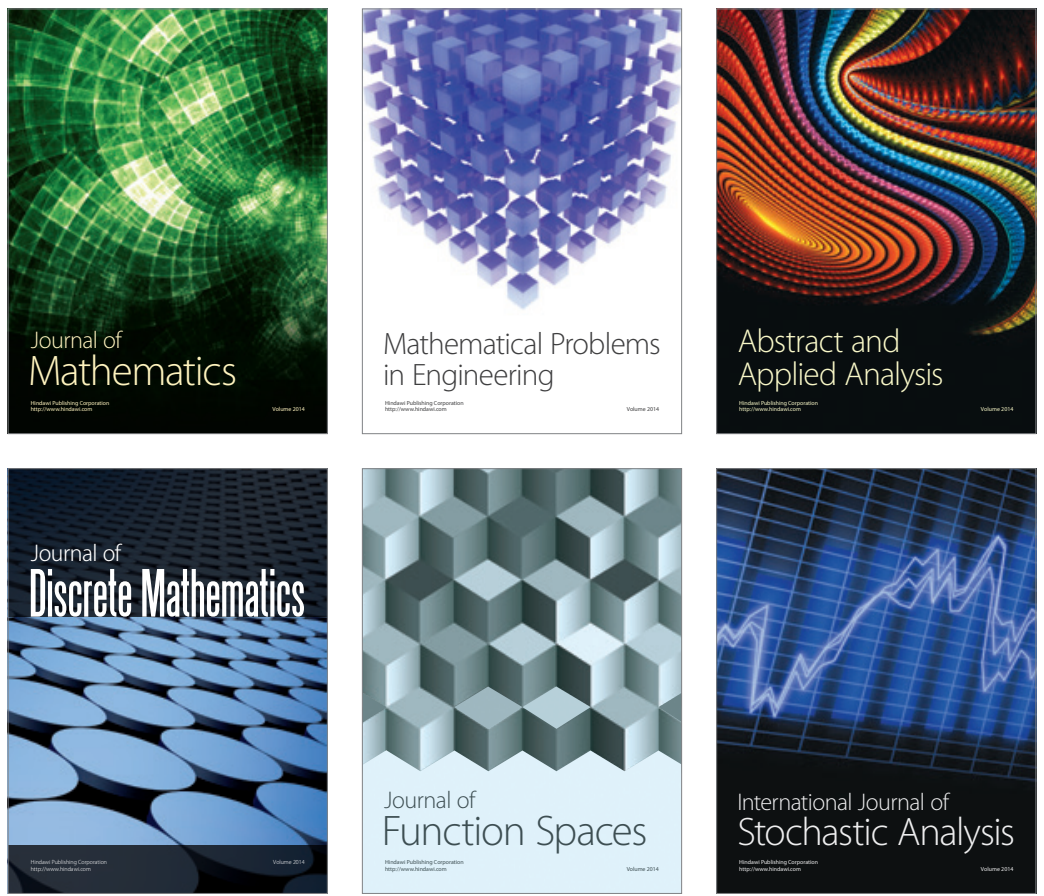

Journal of

Function Spaces

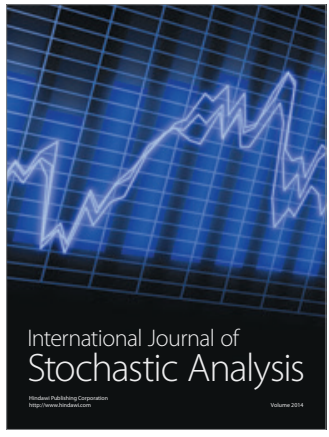

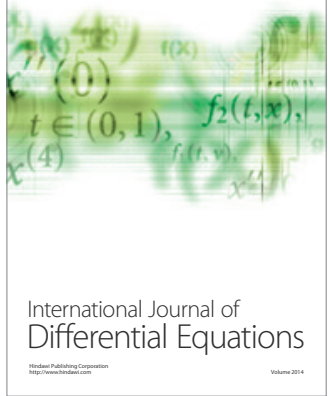
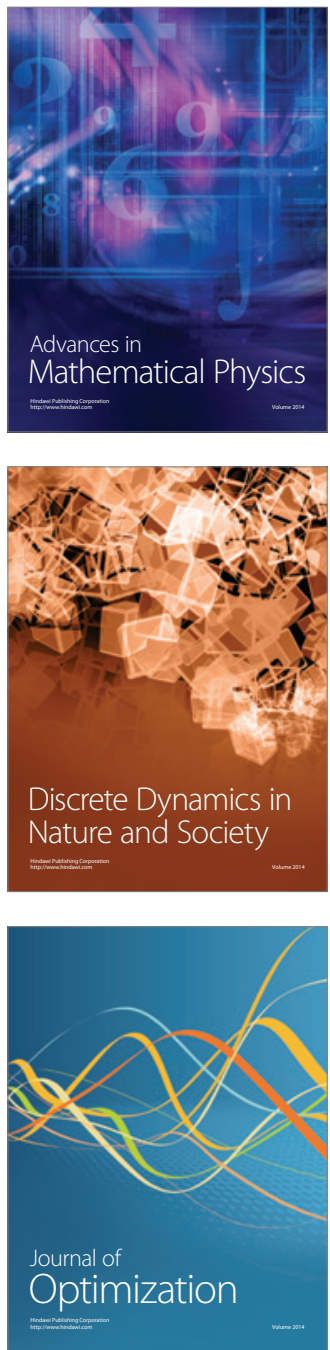